\title{
Topic: EDUCATIONS FROM THE SPECIALISTIC SOCIETY AND FROM THE UNIVERSITY
}

\author{
(c) Springer-Verlag 2014
}

\section{PO:43}

\section{BENEFITS OF LOCAL AND OVERSEAS \\ SURGICAL TRAINING. ACTIVITIES \\ OF "SURGEONS IN ACTION"}

AND "HERNIA INTERNATIONAL" MISSIONS

T. Butron ${ }^{1}$, E. Rubio, JM F Cebrian², J Torres ${ }^{3}$, MA Vaquero ${ }^{3}$,

M. L Vizcayno ${ }^{4}$, J. Garijo ${ }^{5}$, V. G Gutierrez', A. Tartas ${ }^{6}$, JA Pascual $^{7}$,

P. Maldonado, L. Latorre, MJ Castillo

'12 de Octubre University Hospital, Cirugía General y Digestivo B,

Madrid, SPAIN

${ }^{2}$ Fundación Hospital Alcorcón, Cirugía General y Digestivo Alcorcón, Madrid, SPAIN

${ }^{3}$ Infanta Sofia University Hospital, Cirugia General y Digestivo Sebastian de la Reyes, Madrid, SPAIN

${ }^{4}$ San Carlos University Hospital, Anestesia, Madrid, SPAIN

${ }^{5}$ Hospital de Torrejón, Madrid, SPAIN

${ }^{6}$ Getafe University Hopistal, Madrid, SPAIN

${ }^{7}$ Clinica CEMTRO, Madrid, SPAIN

Introduction: The chief aim of our missions is to operate upon patients with low economic resources, but we also carry out teaching for the local staff and residents as well as for the residents and students that come with us. We here present our experience in this field.

Methods: We analyse all the missions carried out since 2009, the number of patients in each, residents, operations, lectures, etc.

Results: From 2009 to 2014 we have carried out 12 missions.

Ecuador, 5 missions: 3 in collaboration with Operation Hernia (OP) (Hernia International HI) and 2 of our own. Three trainees came with us, two surgeons and one family medical doctor. The number of patients operated upon was 454 with 482 procedures: 204 inguinal hernias, 14 femoral, 120 umbilical, 35 epigastric, 33 Incisional, 48 others pathologies.

Nigeria, 2 missions in collaboration with OP: 1 trainee came with us and we taught to 4 local trainees. We operate 84 patients with
95 procedures: 79 inguinal hernias, 6 femoral, 3 epigastric, 1 Incisional, 7 others pathologies.

Mongolia, 2 missions in collaboration with OP. We taught 5 local trainees; and 8 staff learned the laparoscopic inguinal hernia technique (TEP). We operate 179 patients, 51 were children. Pathologies were from abdominal wall and urology. We gave 6 lectures

Camerún, 2 missions of our own. 1 trainee come with us. The number of patients operated upon was 58: 16 inguinal hernias, 1 femoral, 3 umbilical, 3 epigastric, 35 others pathologies.

Peru, 1 mission of our own, 2 trainees came with us and 1 medical student, we taught 5 local trainees. We operated 87 patients with 95 procedures: 54 inguinal hernias. 4 femoral, 22 umbilical, 9 epigastric, 4 Incisional, 16 others pathologies. We gave 2 lectures about negative pressure therapy and anterior component separation technique.

Discusion: All the trainees agreed that this had been a very good experience for them. Our own trainees said they had performed many operations in a short time, saving resources; our own and the local trainees learned how to use mosquito nets as meshes for hernia repair and to compare them with commercial meshes. Our own trainees had the opportunity to see different health systems and to get in contact with the local residents, thus exchanging experiences. The number of our own residents and students is still very low, and it would be convenient if this type of experiences would be introduced in the rotation that taken place during their training. It was also very good experience for the students because they got a better perspective that will help them in their future. The local residents were very interested in seeing different approaches. Increasing international travel and migration have contributed to understand the disparities and inequities in global health systems, and the importance of cross-cultural sensitivity.

Conclusion: Humanitarian missions help the trainees and the students to open their minds, save resources and act more efficiently. It would be desirable if rotation in this kind of missions were compulsory for medical students and trainees. 